12

\title{
Содержание и изотопные отношения благородных газов в конжеляционном льду озера Восток
}

\author{
(С) Ю.О. Четвериков, ${ }^{1}$ Н.Н. Аруев, ${ }^{5}$ C.А. Булат, ${ }^{1}$ К.А. Груздов, ${ }^{4}$ В.Ф. Ежов, ${ }^{1}$ Ф. Жан-Баптист, ${ }^{2}$ И.Л. Каменский, ${ }^{6}$ \\ В.Я. Липенков, ${ }^{3}$ Э.М. Прасолов, ${ }^{4}$ В.А. Соловей, ${ }^{1}$ Р.В. Тюкальцев, ${ }^{5}$ И.Л. Федичкин ${ }^{5}$
}

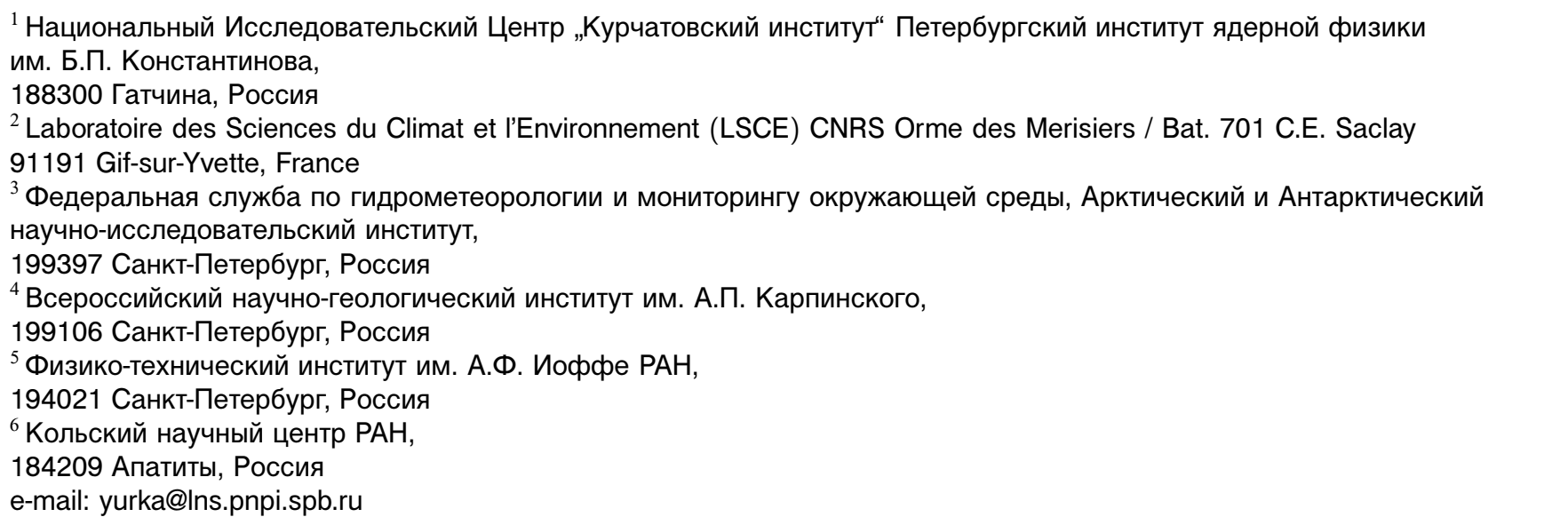

(Поступило в Редакцию 2 октября 2017 г.)

Исследованы изотопные соотношения благородных газов - гелия, неона и аргона, в газовых пробах, полученных дегазацией кернов намерзшей на ледник воды озера Восток. Газы собраны в стеклянные колбы в течение трех дней дегазации кернов, только что поднятых из скважины. Изотопные соотношения ${ }^{3} \mathrm{He} /{ }^{4} \mathrm{He}=0.28 \pm 0.08 \mathrm{R}_{\mathrm{A}} \quad\left(\mathrm{R}_{\mathrm{A}}=1.38 \cdot 10^{-6}\right.$ - отношение для воздуха $)$ в пределах ошибки соответствуют значениям, измеренным в работе [1]. Найденное в пробах отношение ${ }^{4} \mathrm{He} /{ }^{20} \mathrm{Ne}=12.4 \pm 4.6 \mathrm{R}_{\mathrm{A}}$, так же как и ${ }^{40} \mathrm{Ar} /{ }^{36} \mathrm{Ar}=1.0074 \pm 0.0023 \mathrm{R}_{\mathrm{A}}$ превышают их содержание в воздухе $\left({ }^{4} \mathrm{He} /{ }^{20} \mathrm{Ne}_{\mathrm{A}}=0.29\right.$; $\left.{ }^{40} \mathrm{Ar} /{ }^{36} \mathrm{Ar}_{\mathrm{A}}=298.6\right)$. Полученные данные по соотношению ${ }^{4} \mathrm{He} /{ }^{20} \mathrm{Ne}$ и ${ }^{40} \mathrm{Ar} /{ }^{36} \mathrm{Ar}$ могут говорить о некотором вкладе терригенного газа в газовый баланс озера, и указывать на высокое содержание древних грунтовых вод в озере. Отношение ${ }^{3} \mathrm{He} /{ }^{4} \mathrm{He}=0.28 \mathrm{R}_{\mathrm{A}}$ означает низкий поток мантийного ${ }^{3} \mathrm{He}$, характерный для областей континентальных платформ, находящихся далеко от активных рифтовых зон.

DOI: 10.21883/JTF.2018.05.45906.2500

\section{Введение}

Эндогенные геологические процессы, такие как землетрясения, геотермальная активность, радиационный распад нестабильных элементов, приводят к образованию и выделению газов в атмосферу Земли. Смещения земной коры создают зоны разрывных нарушений, по которым движутся насыщенные газами флюиды. Вместе с флюидами газы, выделяемые из земных недр, попадают в покрытое ледником озеро Восток. Газо- и водообмен между движущимся ледником и озером приводит к перемешиванию газов озера и ледника и выносу ледником образовавшегося терригенного газа. Знание содержания газов в замерзшей воде озера (конжеляционном льду) позволит получить комплексную информацию как о геологической активности подстилающих пород, так и о процессах газо- водообмена между озером и окружающей средой.

Основной проблемой при определении содержания и изотопных соотношений газов во льду и воде озера является подвижность газов, приводящая к неизбежной утере части пробы в процессе пробоотбора, смешиванию пробы с воздушными газами в процессе транспортировки и хранения проб. В ледяном керне подвижность газов приводит к выходу части газа в окружающую среду в течение нескольких суток, причем в первые часы подъема бурового снаряда с керном из скважины скорость дегазации керна будет максимальной.

Задача настоящей работы - исследовать благородные газы проб глубоких кернов скважины „Восток“. Пробы получены дегазацией только что поднятых кернов и содержат легкие газы - гелий и неон, которые при хранении кернов в течение нескольких дней уходят в атмосферу.

Исследованные в настоящей работе керны извлечены с глубин 3596-3690 m скважины 5Г-3 станции Восток, Восточная Антарктида, и представляют конжеляционный лед I типа (образец с глубины $3596 \mathrm{~m}$; диапазон глубин 3539-3608 m), содержащий минеральные включения, и очень чистый лед II типа (три образца с глубин 3625, 3651, 3690, ранг глубин 3609-3769 m). Оба типа льда состоят из больших монокристаллов с неровными границами. Минеральные включения заклю- 


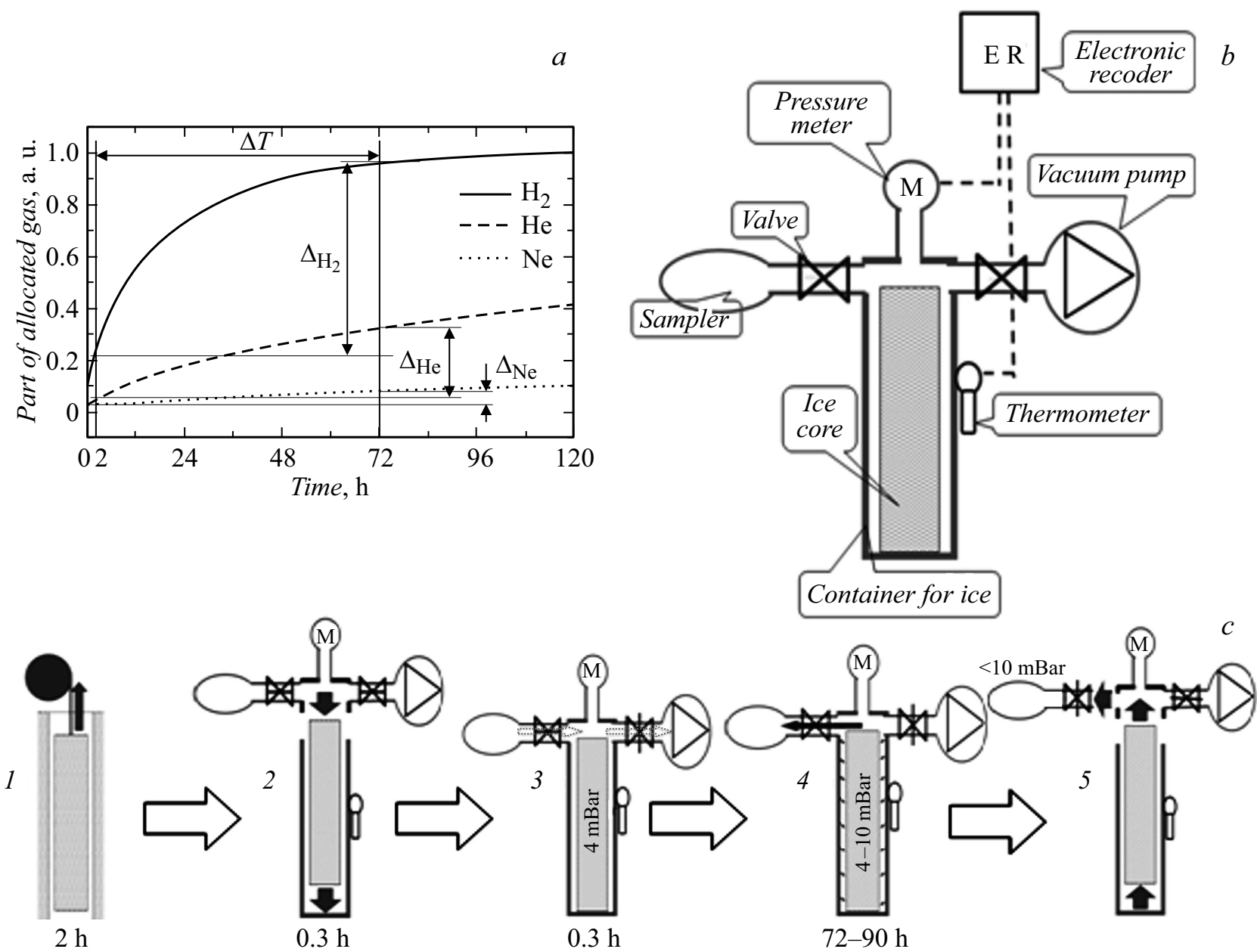

Рис. 1. Технология газового пробоотбора. Модель дегазации ледяного керна $(a)$; схема используемого оборудования $(b)$; последовательность газового пробоотбора $(c)$ : поднятие ледяного керна из скважины $(1)$; помещение керна в герметичный контейнер с последующей вакуумной откачкой $(2,3)$; накопление выделяющихся газов (4); запирание газов в пробоотборнике и разбор оборудования (5).

чены в матрицу монокристаллов. Лед I типа содержит относительно малое количество растворенных газов, а лед II типа - содержит еще на порядок меньше газов, чем лед I типа [2].

\section{1. Методы исследования}

Главным недостатком разработанных ранее технологий газопробоотбора является необходимость разрушения части ледяного керна для приготовления цилиндрического сегмента, помещающегося в герметичную емкость для последующего анализа [3,4]. В процессе приготовления часть газов выходит из образца льда, что снижает точность анализа. Кроме того, помещенный в герметичную емкость лед расплавляется, и, таким образом, безвозвратно теряется информация о его изначальной структуре и пористости, определяющей скорость выхода газа.
Для того чтобы избежать перечисленных недостатков в ПИЯФ была разработана технология неразрушающего керн пробоотбора подвижных газов [5]. Идея такого пробоотбора заключается в сборе газа, выделяющегося из керна после его подъема. На рис. 1, $a$ приводится график, отображающий модель дегазации цилиндрического фрагмента льда размером с керн $(D=0.1 \mathrm{~m}$; $h=1 \mathrm{~m})$ : доля вышедшего из керна газа $\left(\mathrm{H}_{2}, \mathrm{He}, \mathrm{Ne}\right)$ в зависимости от времени дегазации. Видно, что в течение $72 \mathrm{~h}$ выходит бо́льшая часть водорода и значительная часть гелия. Доля газов, попадающих в пробоотборник, обозначена как $\Delta$.

У этой технологии есть несколько исключительных особенностей (рис. 1) по сравнению с технологией фрагментации ледяного керна на маленькие сегменты использование больших ледяных фрагментов керна обеспечивает большую сохранность газов, не теряющихся в ходе изготовления; механическая очистка поверхности керна позволяет значительно уменьшать 
концентрацию газов загрязнения, которые содержатся в буровой жидкости и большей части приповерхностного слоя; для определения содержания водорода необходимо использовать только не разрушенный атмосферный либо конжеляционный лед. Технология впервые применена во время работ 58-го РАЭ (2012-2013) на станции Востока (ледяные керны интервала глубин 3457-3484 m), была улучшена в течение сезона 59-го РАЭ (2013-2014) с использованием ледяных кернов в диапазоне глубин 3596-3698 m.

Состав выделившихся газов отличается от состава в ледяном керне. Это происходит потому, что образцы собираются в ограниченном по времени интервале приблизительно $72 \mathrm{~h}$. В течение этого времени бо́льшая часть легких газов выходит из образца, тогда как бо́льшая часть тяжелых газов продолжает оставаться во льду. В модели диффузии (уравнение (5.33) [6]) можно вычислить смесь газов, которые вышли изо льда, взяв экспериментальные значения коэффициентов распространения различных газов во льду [7-9]. Предположительная доля газов, выходящих из керна в течение первых $72 \mathrm{~h}$ с момента подъема, составляет для водорода около 90\%, для гелия около $30 \%$ и порядка $10 \%$ для менее подвижных газов. Полученная таким образом газовая смесь поступает в пробоотборник и в дальнейшем исследуется в лабораторных условиях.

Анализ газового состава проб производился на времяпролетном масс-спектрометре ФТ-1 ФТИ им. А.Ф. Иоффе через 6 месяцев после пробоотбора [5]. Через 9-15 месяцев - на спектрометрах MAP-215-50 (LSCE, CEA Сакле, Франция), Micromass' NG-5400, ВСЕГЕИ (Санкт-Петербург) и МИ 1201, ГИ КНЦ РАН (Апатиты) были измерены содержания и изотопные отношения благородных газов в тех же пробах. На спектрометрах МИ 1201 и МАР-215-50 измерялись изотопы ${ }^{3} \mathrm{He},{ }^{4} \mathrm{He}$ и ${ }^{20} \mathrm{Ne}[10,11]$, тогда как на спектрометре Micromass в дополнение к ${ }^{3} \mathrm{He},{ }^{4} \mathrm{He}$ и ${ }^{20} \mathrm{Ne}$ измерялись изотопы ${ }^{36} \mathrm{Ar}$ и ${ }^{40} \mathrm{Ar}$.

\section{2. Полученные результаты}

На рис. 2 представлены результаты измерений содержания ${ }^{4} \mathrm{He}$ и изотопных отношений ${ }^{3} \mathrm{He},{ }^{4} \mathrm{He},{ }^{20} \mathrm{Ne}$ и ${ }^{40} \mathrm{Ar}$, а также давления проб в зависимости от глубины взятия керна. Из полученных данных так же видно, что значения содержания ${ }^{4} \mathrm{He}$ и изотопных соотношений пробы изо льда типа I с глубины 3596 m мало отличаются от значений для проб льда типа II. В табл. 1 сведены результаты всех проделанных измерений. Значения изотопных отношений на рис. 2 и в табл. 1 приведены в единицах атмосферных отношений. Найденные значения - результат усреднения всех измерений, ошибка измерения определена как дисперсия вокруг среднего значения.
Таблица 1. Средние значения измеренных величин по четырем пробам с глубин 3596, 3625, 3651 и $3690 \mathrm{~m}$

\begin{tabular}{c|c|c}
\hline $\begin{array}{c}\text { Измеренная } \\
\text { величина }\end{array}$ & $\begin{array}{c}\text { Найденное } \\
\text { значение }\end{array}$ & $\begin{array}{c}\text { Единица } \\
\text { измерения }\end{array}$ \\
\hline$P_{\mathrm{WAP}}^{*}$ & $0.036 \pm 0.009$ & Atm \\
$P_{\mathrm{DAP}}^{* * *}$ & $0.014 \pm 0.08$ & $\mathrm{Atm}$ \\
$t_{\mathrm{SAM}}^{* * *}$ & $-23 \pm 3$ & ${ }^{\circ} \mathrm{C}$ \\
$d P_{\mathrm{DG}}^{* * * *}$ & $<0.001$ & $\mathrm{Atm}$ \\
${ }^{4} \mathrm{He}$ & $132 \pm 31$ & $\mathrm{nM} / \mathrm{L}_{\mathrm{ice}}$ \\
${ }^{3} \mathrm{He} /{ }^{4} \mathrm{He}$ & $0.29 \pm 0.08$ & $R_{\mathrm{A}}=1.38 \cdot 10^{-6}$ \\
${ }^{4} \mathrm{He} /{ }^{20} \mathrm{Ne}$ & $12.4 \pm 4.6$ & $R_{\mathrm{A}}=0.288$ \\
${ }^{20} \mathrm{Ne} /{ }^{4} \mathrm{Ne}$ & $0.08 \pm 0.03$ & $R_{\mathrm{A}}=3.47$ \\
${ }^{3} \mathrm{He} /{ }^{20} \mathrm{Ne}$ & $3.7 \pm 0.8$ & $R_{\mathrm{A}}=4.04 \cdot 10^{-7}$ \\
${ }^{20} \mathrm{Ne} /{ }^{40} \mathrm{Ar}$ & $1.3 \pm 0.2$ & $R_{\mathrm{A}}=1.95 \cdot 10^{-3}$ \\
${ }^{40} \mathrm{Ar} /{ }^{36} \mathrm{Ar}$ & $1.0074 \pm 0.0023$ & $R_{\mathrm{A}}=298.6$ \\
& &
\end{tabular}

Примечание: * - давление влажного воздуха в пробах во время измерений, ** - давление сухого воздуха во время измерений, *** — температура льда во время пробооборота, **** — увеличение давления в контейнере со льдом во время пробооборота (за счет дегазации керна).

\section{3. Обсуждение}

\section{1. Газообмен между озером и окружающей средой и изотопная систематика $\mathrm{He}-\mathrm{Ne}-\mathrm{Ar}$}

Соотношение изотопов ${ }^{3} \mathrm{He} /{ }^{4} \mathrm{He}$ в породах и флюидах Земли несет в себе информацию о тепловом потоке в районе взятия пробы. Вместе с тепловым потоком из глубин Земли к поверхности дрейфует мантийный гелий, обогащенный ${ }^{3} \mathrm{He}$ изотопом. Это обогащение и является индикатором теплового потока. В соответствии с [12] из отношения ${ }^{3} \mathrm{He} /{ }^{4} \mathrm{He}$ в земных флюидах тепловой поток может быть вычислен по формуле

$$
q\left(\mathrm{~mW} / \mathrm{m}^{2}\right)=18.231 \cdot \lg \left({ }^{3} \mathrm{He} /{ }^{4} \mathrm{He}\right)+181.82 .
$$

Значение теплового потока коррелирует с тектоническим возрастом. Большой тепловой поток наблюдается в местах тектонических разломов и сравнительно молодых районах, где продолжают происходить активные тектонические процессы.

Кроме мантии в недрах Земли существует и другой значительный источник образования гелия - распад радиоактивных элементов, содержащихся в земной коре. Распад приводит к обогащению содержащихся в породах и флюидах газов изотопом ${ }^{4} \mathrm{He}$. Содержание ${ }^{4} \mathrm{He}$ в грунтовой воде описывается уравнением [13]:

$$
\begin{aligned}
{\left[{ }^{4} \mathrm{He}_{\mathrm{ROCK}}\right] } & =(12.1 \cdot[U]+2.9[T h]) \\
& \times\left\{(1-p) D_{\mathrm{R}} /\left(p \cdot D_{\mathrm{W}}\right)\right\}(1-L) T \cdot 10^{-8},
\end{aligned}
$$

где $D_{\mathrm{W}}$ - плотность грунтовой воды $(1 \mathrm{~g} / \mathrm{cm} 3)$. Описание и модельные значения других параметров формулы даны 

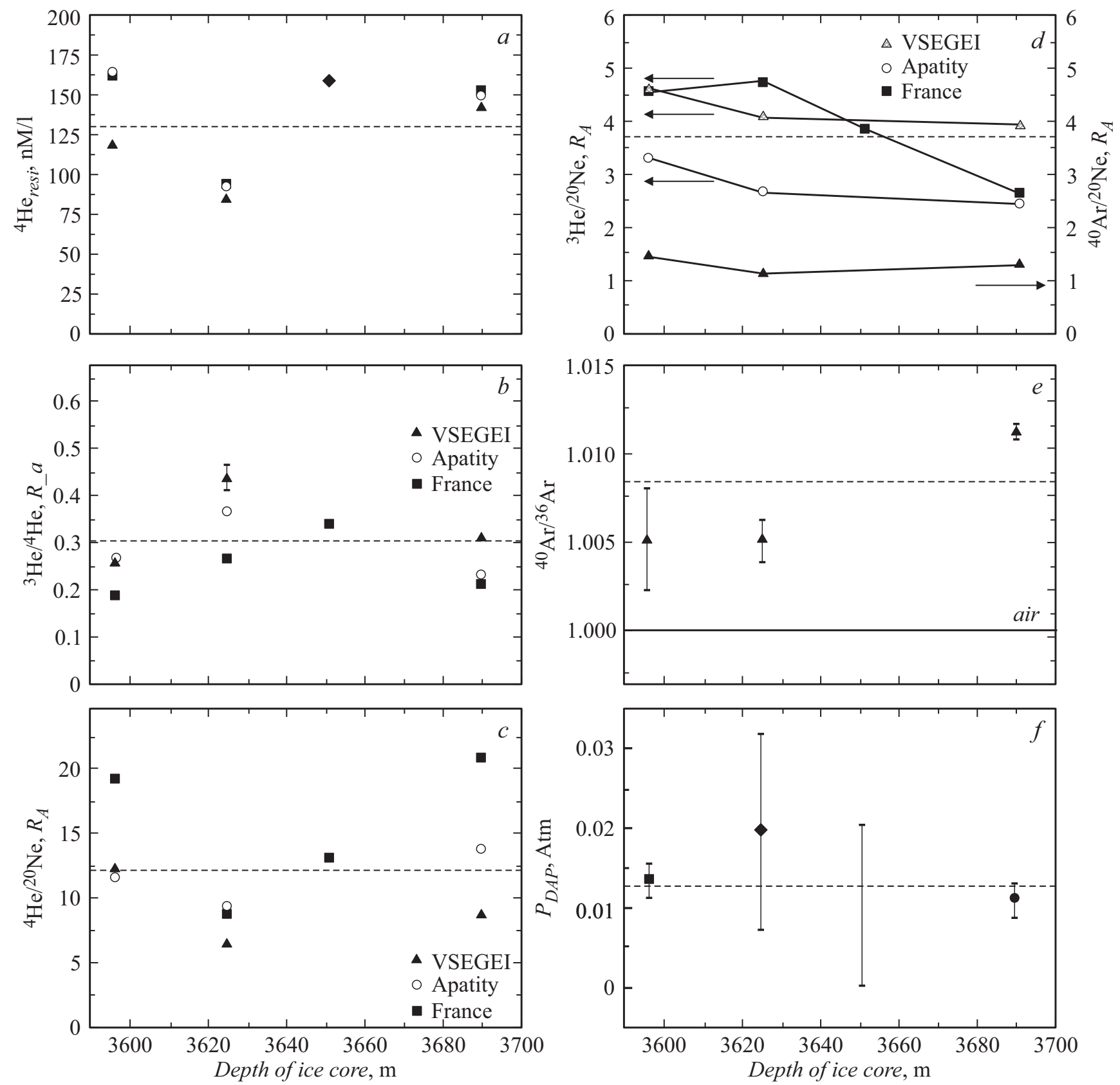

Рис. 2. Содержание ${ }^{4} \mathrm{He}$, соотношения изотопов и давление в пробах в зависимости от глубины взятия керна: $a$ - восстановленное содержание ${ }^{4} \mathrm{He} ; b-{ }^{3} \mathrm{He} /{ }^{4} \mathrm{He} ; c-{ }^{4} \mathrm{He} /{ }^{20} \mathrm{Ne} ; d-{ }^{3} \mathrm{He} /{ }^{20} \mathrm{Ne} ; e-{ }^{40} \mathrm{Ar} /{ }^{36} \mathrm{Ar} ; f-$ давление сухого воздуха в пробах во время измерений.

в табл. 2. Из вычисленного значения мощности грунтовых вод $H_{\mathrm{GW}}=H_{\mathrm{W}} p$, где $H_{\mathrm{W}}-$ глубина водосодержащих пород под дном озера, можно найти поток гелия из подстилающих пород $\Phi_{4} \mathrm{He}=\left[{ }^{4} \mathrm{He}_{\mathrm{ROCK}}\right] H_{\mathrm{GW}} / T$.

Накопление ${ }^{4} \mathrm{He}$, образованного при распаде радиоактивных элементов, является индикатором возраста пород и флюидов, содержащихся в земной коре.

Таким образом, можно отметить три существенных источника изотопов гелия в земных флюидах - атмосфера Земли, газы земной мантии и продукты распада радиоактивных руд в земных породах. Каждый источник имеет свое характерное изотопное отношение ${ }^{3} \mathrm{He} /{ }^{4} \mathrm{He}$ и отношение с атмогенными изотопами, такими как ${ }^{20} \mathrm{Ne}$ [14]. Выявление долей смешивания атмосферных газов с газами других источников может позволить определить как тепловой поток, так и возраст исследуемых пород и флюидов.

Озерная вода находится в равновесии с грунтовой водой, т. е. наработанные в породах газы равномерно перемешиваются в водной системе грунтовая вода-озеро. 
Таблица 2. Параметры геофизических моделей озера Восток

\begin{tabular}{|c|c|c|c|}
\hline \multicolumn{2}{|c|}{ Параметры } & \multicolumn{2}{|c|}{ Модель } \\
\hline Наименование & Обозначение & $\begin{array}{c}\text { Активного рифта, } \\
\text { байкальского типа (BL) }\end{array}$ & $\begin{array}{c}\text { Депрессии континетальной } \\
\text { платформы }(\mathrm{CL})\end{array}$ \\
\hline Тепловой поток & $q$ & $64-84 \mathrm{~mW} / \mathrm{m}^{2}[19]$ & $50-60 \mathrm{~mW} / \mathrm{m}^{2}[20,21]$ \\
\hline $\begin{array}{c}\text { Время обновления воды } \\
\text { в объеме озера }\end{array}$ & $T$ & $\begin{array}{c}100000-125000 \text { years } \\
{[24,25]}\end{array}$ & $\begin{array}{c}100000-125000 \text { years } \\
{[24,25]}\end{array}$ \\
\hline Пористость породы & $p$ & $0.07-0.13[13]$ & $0.006-0.012[27]$ \\
\hline Глубина озера & $H_{\mathrm{L}}$ & $415 \mathrm{~m}$ & $415 \mathrm{~m}$ \\
\hline $\begin{array}{c}\text { Глубина водосодержащих } \\
\text { пород под дном озера }\end{array}$ & $H_{\mathrm{C}}$ & $6000 \mathrm{~m} \mathrm{[30]}$ & $6000 \mathrm{~m}[27]$ \\
\hline Мощность толщи & $H_{\mathrm{GW}}=p H_{\mathrm{C}}$ & $600 \mathrm{~m}$ & $54 \mathrm{~m}$ \\
\hline Плотность донных пород & $D_{\mathrm{R}}$ & $2.6 \mathrm{~g} / \mathrm{cm}^{3}$ & $2.6 \mathrm{~g} / \mathrm{cm}^{3}$ \\
\hline Кларк Урана & $U$ & $5.6-9.8[31]$ & $2.8-4 \mathrm{ppm}[32]$ \\
\hline Кларк Тория & $T h$ & $1.53 \mathrm{xU}[31]$ & $9.6 \mathrm{ppm}[32]$ \\
\hline $\begin{array}{c}\text { Коэффициент } \\
\text { удержания Не }\end{array}$ & $L$ & 0.1 [рис. 8.6 Mam\&Tolst84] & 0.1 (рис. $8.6[14])$ \\
\hline $\begin{array}{c}\text { Поток }{ }^{4} \text { Не из донных } \\
\text { пород }\end{array}$ & $\Phi_{4_{\mathrm{He}}}=\left[{ }^{4} \mathrm{He}_{\mathrm{rock}}\right] H_{\mathrm{GW}} / T$ & $0.77 \mathrm{mkM} / \mathrm{m}^{2}$ year & $0.46 \mathrm{mkM} / \mathrm{m}^{2}$ year \\
\hline
\end{tabular}

Примечание: * — время рассчитано исходя из предложения, что озеро замкнуто и объем водной системы равен объему озера.

Время обновления газа по аналогии с уравнением (4) [1] определяется как

$$
\begin{aligned}
T_{\mathrm{G}}= & \left(\left(1-\beta^{\prime}\right) C_{\mathrm{ice}}^{\prime \prime}+\beta^{\prime} C_{\mathrm{GW}}^{\prime \prime}-\left(1-\alpha^{\prime}\right) C_{\mathrm{ice}}^{\prime}-\alpha^{\prime} C_{\mathrm{GW}}^{\prime}\right) \\
& \times \rho\left(H_{\mathrm{L}}+H_{\mathrm{GW}}\right) /\left(\Phi_{\mathrm{G}}-\Phi_{\mathrm{dif}}\right),
\end{aligned}
$$

где $C^{\prime}, C^{\prime \prime}$ - концентрации газа во входящих и исходящих из озера потоках: $C_{\text {ice }}^{\prime \prime}-$ в уносимом ледником конжеляционном льду, $C_{\mathrm{GW}}^{\prime \prime}-$ в утекающей из озера подледниковой воде, $C_{\text {ice }}^{\prime}-$ в воде из растаявшего над озером льда ледника, $C_{\mathrm{GW}}^{\prime}-$ в воде, втекающей в озеро из под ледника, $\alpha^{\prime}, \beta^{\prime}$ - доля газа, притекающего и утекающего с подледной водой в ледниково-водных входящих и исходящих потоках соответственно, $\rho-$ плотность воды озера, $H_{\mathrm{L}}$ и $H_{\mathrm{GW}}-$ средняя глубина озера и мощность грунтовых вод под озером. $\Phi_{\mathrm{G}}-$ поток газа, наработанного в породах, $\Phi_{\text {Dif }}-$ поток диффузии газа из воды в ледник. Озеро Восток считается замкнутым водоемом, поэтому для коэффициентов $\alpha^{\prime}, \beta^{\prime}$ задаются значения близкие или равные нулю [1]. Таким образом, основным каналом исходящего из озера потока газов является уносимый ледником конжеляционный лед.

Отношение газов в конжеляционном льду оказываются другим, чем в воде. Легкие газы находятся во льду в растворенном состоянии [15], тогда как тяжелые газы не растворяются во льду и содержатся в солевом растворе между зерен льда [2]. Распределение газа во льду может быть записано как $\left(1-\beta^{\prime}\right)=\beta_{\mathrm{S}}^{\prime \prime}+\beta_{\mathrm{BC}}^{\prime \prime}$, где $\beta_{\mathrm{S}}^{\prime \prime}, \beta_{\mathrm{B}}^{\prime \prime}-$ доли газа, растворенного во льду и в межзерновом солевом растворе соответственно, а отношение растворенных во льду газов к растворенным в воде может быть записано как

$$
\begin{gathered}
C_{\mathrm{ice}}^{\prime \prime}=C_{\mathrm{iceS}}^{\prime \prime}+C_{\mathrm{ice} \mathrm{B}}^{\prime \prime}, \\
C_{\mathrm{ice}}^{\prime \prime}=\left(S_{\mathrm{I}} / S_{\mathrm{W}} C_{\mathrm{LW}},\right. \\
C_{\mathrm{ice \textrm {B }}}^{\prime \prime}=\left(d V_{\mathrm{B}} / d V_{\mathrm{ice}}\right) C_{\mathrm{B}},
\end{gathered}
$$

где $C_{\mathrm{ice}}^{\prime \prime}, C_{\mathrm{ice}}^{\prime \prime} C_{\mathrm{LW}}, C_{\mathrm{B}}-$ концентрации газа растворенного во льду, находящегося в межзерновом солевом растворе льда, в воде озера и чистом солевом растворе соответственно; $S_{\mathrm{I}} / S_{\mathrm{W}}$ - отношение растворимостей газа в воде и льду, $d V_{\mathrm{B}} / d V_{\text {ice }}$ - доля солевого раствора во льду. Различие в растворимостях газа во льду и воде приводит к разности между временем обновления воды и газа. В случае хорошо растворимых во льду легких газов $\left(\mathrm{H}_{2}, \mathrm{He}\right)$ с $C_{\mathrm{ices}}^{\prime \prime} \gg C_{\mathrm{ice}}^{\prime \prime}$ время обновления газа может быть записано как

$$
T_{\mathrm{G}}=T_{\mathrm{W}}\left(S_{\mathrm{W}} / S_{\mathrm{I}}\right)
$$

Это означает, что для гелия в озере время обновления в 1.76 раза меньше [15], чем воды. Для тяжелых газов, не растворимых в воде $\left(C_{\mathrm{ices}}^{\prime \prime} \ll C_{\mathrm{iceB}}^{\prime \prime}\right)$, время обновления находится как

$$
T_{\mathrm{G}}=T_{\mathrm{W}}\left(d V_{\mathrm{ice}} / d V_{\mathrm{B}}\right) C_{\mathrm{LW}} / C_{\mathrm{B}}
$$




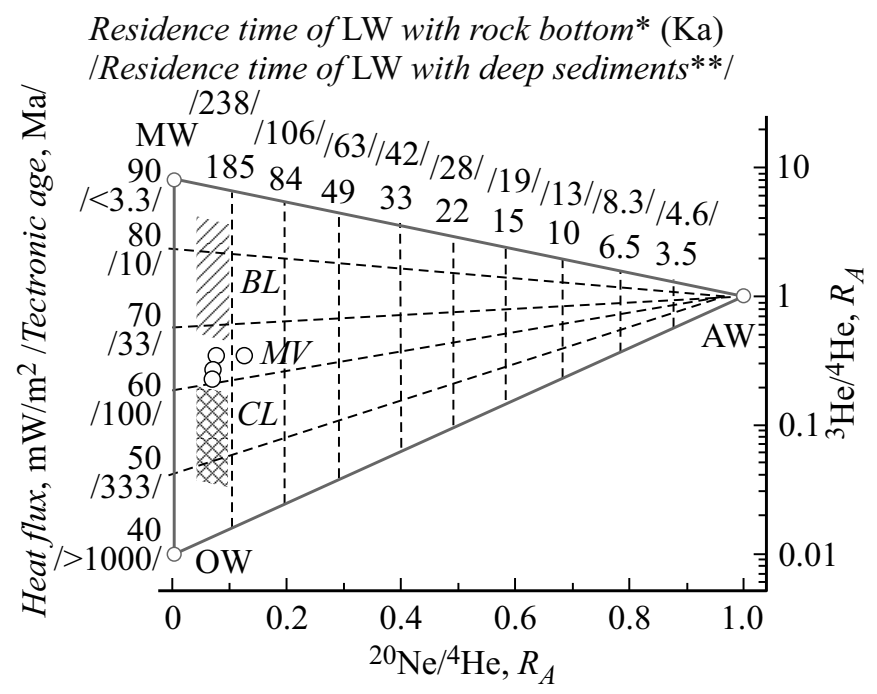

Рис. 3. Гелий-неоновая изотопная систематика и геофизические характеристики озера. Точки MV -- измеренные значения четырех проб, точка AW - вода, насыщенная атмосферными газами, OW - вода, насыщенная радиогенными газами земной коры; MW - вода, насыщенная мантийными газами. Верхние шкалы - модельный возраст грунтовых вод в трещинах скальных пород и глубоких донных осадках в соответствии с уравнениями (2), (3) и табл. 2. Заштрихованные области допустимые значения геофизических моделей. Левая шкала тепловой поток и тектонический возраст подстилающих пород в соответствии с (1) и [14].

в случае конжеляционного льда озера Восток $d V_{\text {ice }} / d V_{\mathrm{B}}$ порядка $10^{6}[2]$, что означает $T_{\mathrm{G}}>T_{\mathrm{W}}$, даже при предельном значении $C_{\mathrm{B}}=0.166 M_{\mathrm{Gas}} / M_{\mathrm{H}_{2} \mathrm{O}}[16]$ клатрата газа во льду.

На рис. 3 построены точки для четырех проб в пространстве координат ${ }^{3} \mathrm{He} /{ }^{4} \mathrm{He}-{ }^{20} \mathrm{Ne} /{ }^{4} \mathrm{He}$, измеренных в настоящей работе. В соответствии с уравнением (3) содержание ${ }^{4}$ Не в грунтовых водах зависит от многих параметров, таких как возраст, содержание радиоактивных элементов, пористость пород и др. В верхней части графика приведены две возрастных шкалы для разных моделей озера, параметры которых представлены в табл. 2. Поскольку озеро Байкал имеет сходные структурные и морфологические характеристики с озером Восток [17], то логично сравнивать полученные результаты для озера Восток с моделью изолированного льдом озера Байкал [18]. В модели активного рифта байкальского типа (BL) предполагается наличие $6 \mathrm{~km}$ осадочного пласта под дном озера со средней пористостью $10 \%$ и содержанием урана и тория, свойственным осадочным породам; тепловой поток в этой модели $76 \pm 10 \mathrm{~mW} / \mathrm{m}^{2}$ - величина, характерная для озера Байкал [19]. В модели депрессии континентальной платформы (CL) предполагается отсутствие осадков на дне, а грунтовая вода находится в трещинах скальных пород дна озера со средней пористостью около $0.9 \%$. до глубины $6 \mathrm{~km}$. Тепловой поток в такой модели -
Таблица 3. Коэффициенты диффузии и расчетные значения доли газа, выделившейся за время пробоотбора из керна кристаллического льда (IC), керна морского льда (SC) и цилиндрического объема воды, соответствующего геометрии керна (LC)

\begin{tabular}{c|c|c|c|c|c|c}
\hline \multirow{2}{*}{$\begin{array}{c}\text { Эле- } \\
\text { мент }\end{array}$} & $\begin{array}{c}\text { D в кристаллах } \\
\text { чистого льда }\end{array}$ & \multicolumn{2}{|c|}{$\begin{array}{c}\text { D в морском } \\
\text { льду }\end{array}$} & \multicolumn{2}{|c}{ D в воде } \\
\cline { 2 - 7 } & $\mathrm{D}, 10^{-9} \mathrm{~m}^{2} / \mathrm{s}$ & $\Delta$ & $\mathrm{D}, 10^{-9} \mathrm{~m}^{2} / \mathrm{s}$ & $\Delta$ & $\mathrm{D}, 10^{-9} \mathrm{~m}^{2} / \mathrm{s}$ & $\Delta$ \\
\hline $\mathrm{H}_{2}$ & $20.5[7]$ & 0.7 & - & - & 5 & 0.65 \\
$\mathrm{He}$ & $1.1[8]$ & 0.28 & - & - & 6.8 & 0.73 \\
$\mathrm{Ne}$ & $0.1[8]$ & 0.05 & - & - & 3 & 0.52 \\
$\mathrm{Ar}$ & $0.01[8]$ & 0.04 & $1.54-1.76[9]$ & 0.36 & 2.6 & 0.49 \\
$\mathrm{~N}_{2}$ & $0.0014[8]$ & 0.01 & $2.49[9]$ & 0.48 & 2.6 & 0.49 \\
$\mathrm{O}_{2} 2$ & $0.0009[8]$ & 0.01 & $1.55-1.74[9]$ & 0.36 & 2.1 & 0.44
\end{tabular}

$56 \mathrm{~mW} / \mathrm{m}^{2}$ - вычисленная величина для района озера Восток [20,21].

Газ полученных проб может содержать некоторое количество терригенного Ar, что выражается в измеренных значениях большего изотопного отношения ${ }^{40} \mathrm{Ar} /{ }^{36} \mathrm{Ar}=1.0074 \pm 0.0023 \mathrm{R}_{\mathrm{A}}$, превышающем атмосферное значение $\left(\mathrm{R}_{\mathrm{A}}\right){ }^{40} \mathrm{Ar} /{ }^{36} \mathrm{Ar}=298.6$ и значения, найденные в толще ледника, вызванные фракционированием изотопов $\mathrm{Ar}[22]$. Из расчета, что атмосферные отношения ${ }^{4} \mathrm{He} /{ }^{20} \mathrm{Ne}$ и ${ }^{40} \mathrm{Ar} /{ }^{36} \mathrm{Ar}$ нарушены присутствием терригенных ${ }^{4} \mathrm{He}$ и ${ }^{40} \mathrm{Ar}$, отношение ${ }^{4} \mathrm{He}_{\text {ter }} /{ }^{40} \mathrm{Ar}_{\text {ter }}=1.4-2.9$. Полученное значение ниже, чем отношение наработанных консолидированной земной корой элементов ${ }^{4} \mathrm{He}_{\mathrm{ec}} /{ }^{40} \mathrm{Ar}_{\mathrm{ec}}=10$ [23]. Однако аргон в отличии от гелия не растворяется во льду и способен накапливаться в озере. Поэтому время обновления аргона в озере должно быть больше времени обновления гелия, что ведет к уменьшению отношения ${ }^{4} \mathrm{He}_{\text {ter }} /{ }^{40} \mathrm{Ar}_{\text {ter }}$ в озере в сравнении с отношением произведенных земной корой гелия и аргона $-{ }^{4} \mathrm{He}_{\mathrm{ec}} /{ }^{40} \mathrm{Ar}_{\mathrm{ec}}$.

Из рис. 3 видно, что измеренные отношения находятся между значениями, полученными в моделях (заштрихованные области на графике). Измеренное значение отношения ${ }^{20} \mathrm{Ne} /{ }^{4} \mathrm{He}$ почти совпадает со средними значениями, полученными в моделях CL и BL. Измеренное отношение ${ }^{3} \mathrm{He} /{ }^{4} \mathrm{He}$ выше, чем у модели CL, но ниже чем у модели BL.

В соответствии с уравнениями (2),(3) и данными моделей из табл. 2 среднему значению отношения ${ }^{20} \mathrm{Ne} /{ }^{4} \mathrm{He}=0.08 \pm 0.03 \mathrm{R}_{\mathrm{A}}$ в модели $\mathrm{CL}$ соответствует время обновления гелия в системе озеро-грунтовая вода $135000 \pm 40000$ years, тогда как для BL модели этот возраст $172000 \pm 50000$ years. Вода озера будет обновляться в течение $232000 \pm 69000$ years в модели CL, либо $296000 \pm 86000$ years в BL модели. Таким образом, время обновления воды более чем в два раза превышает найденные в работах [24,25] значения в $100000-125000$ years. 
Значения ${ }^{20} \mathrm{Ne} /{ }^{4} \mathrm{He}$ в модели без осадков на дне - CL и модели с глубокими осадками BL близки друг к другу, поэтому это отношение не чувствительно к наличию осадков. Для выявления пористых донных осадков, наряду с сейсмическими исследованиями [17] и расчетами геойда, основанными на альтиметрических и радиолокационных измерениях [18], может быть проанализировано измеренное $\mathrm{H}_{2} /{ }^{4} \mathrm{He}$ отношение в воде и льду озера. Из найденного в [5] соотношения $\mathrm{H}_{2} /{ }^{4} \mathrm{He}=5.4 \pm 1.9$ для конжеляционного льда, согласно уравнениям (3), (4) из [26] и значениям кларка урана и тория, соответствующим CL модели, дно озера обладает пористостью $p=0.014 \%$, свойственной низкопористым скальным породам. Близкие значения соотношения $\mathrm{H}_{2} /{ }^{4} \mathrm{He}$ наблюдаются в докембрийских породах других континентальных областей Земли [27].

Найденное соотношение ${ }^{3} \mathrm{He} /{ }^{4} \mathrm{He}$ находится близко к обеим предложенным моделям. В соответствии с (1) расчетное значение теплового потока для найденного значения ${ }^{3} \mathrm{He} /{ }^{4} \mathrm{He}=0.29 \pm 0.08 \mathrm{R}_{\mathrm{A}}$ будет $62.6 \mathrm{~mW} / \mathrm{m}^{2}$, что выше значения $56 \mathrm{~mW} / \mathrm{m}^{2}$, рассчитанного по динамике движения ледника, но значительно ниже, чем значения теплового потока активных рифтовых зон в $70-90 \mathrm{~mW} / \mathrm{m}^{2}$.

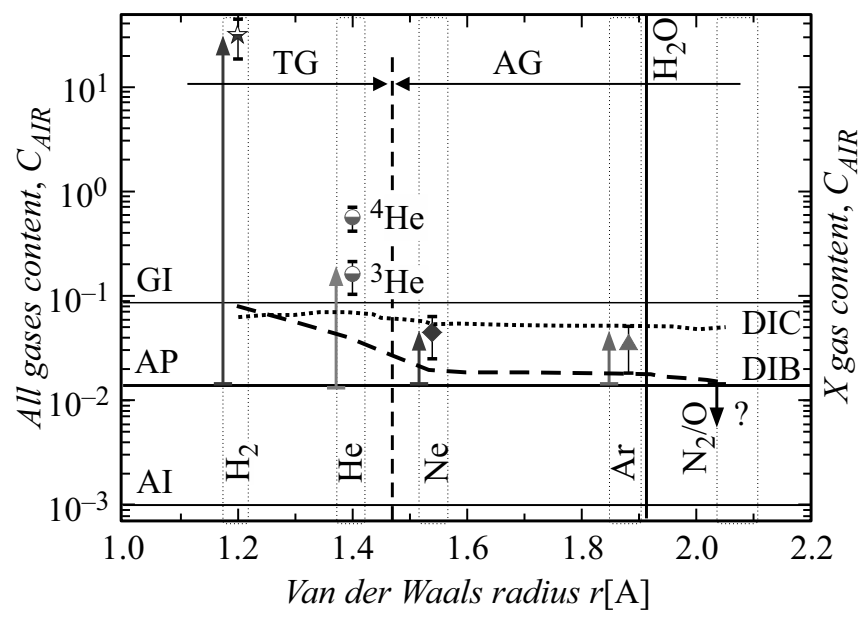

Pис. 4. Содержание газов в пробах как функция ван-дервальсового радиуса молекулы газа. Точки на графике - измеренные значения, нормированные на содержание газа в атмосфере (значение $\mathrm{H}_{2}$ из работы [5]). Уровни GI и $\mathrm{AI}-$ уровни общего газо-содержания атмосферного и конжеляционного льда соответственно. АР - уровень атмосферного загрязнения проб. Линии DIC и DIB - значения газосодержания в моделях выделения газа либо из кристаллов льда (DIC), либо из межзернового рассола (DIB), рассчитанные из уравнения (5.33) работы [6] и коэффициентов диффузии табл. 3. Стрелки вверх рядом с точками указывают на обогащение газовой смеси соответствующим газом $\left(\mathrm{H}_{2}, \mathrm{He}, \mathrm{Ne}, \mathrm{Ar}\right)$ относительно воздушной смеси; стрелки вниз - обеднение газами $\left(\mathrm{O}_{2}, \mathrm{~N}_{2}\right)$. TG - газы с наибольшим терригенным вкладом, AG - газы с наибольшим атмогенным вкладом. Толстая вертикальная линия - радиус молекулы воды.

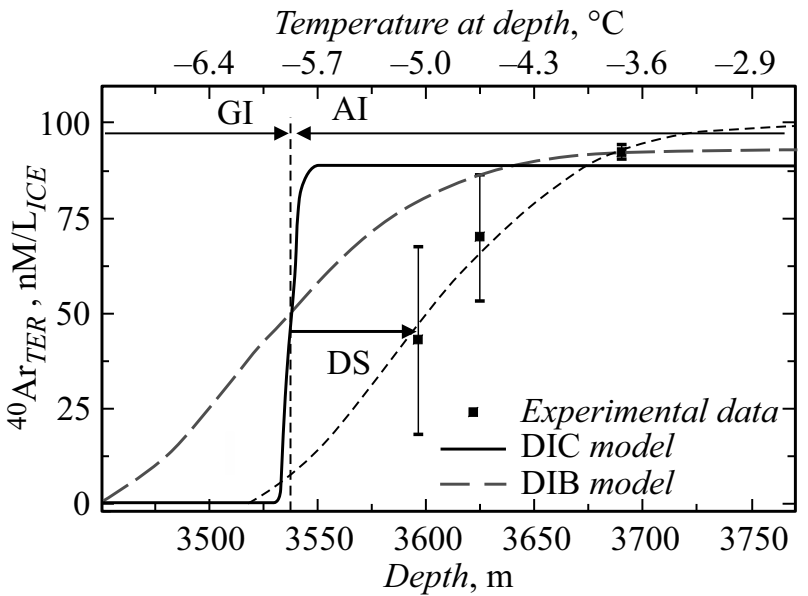

Рис. 5. Предполагаемый глубинный профиль области распространения терригенного ${ }^{40} \mathrm{Ar}$. Точки - экспериментальные данные, кривые линии - модели распространения. DIC модель диффузии в кристаллическом льду; DIB - модель диффузии в солевом растворе межзерновой области. GI/AI граница между атмосферным и конжеляционным льдом; DS несоответствие по глубине центра границы распространения терригенного аргона с границей атмосферного и конжеляционного льда.

\section{2. Газопроницаемость конжеляционного льда озера Восток}

Как было написано ранее, лишь малая часть тяжелых и слабоподвижных газов должна выходить из кристаллов льда керна в исследованные пробы (табл. 3). Однако наблюдаемые содержания атмогенных газов (рис. 4) значительно выше, чем значения, рассчитанные из диффузионной дегазации кристаллов льда, насыщенного теми же газами, что и атмосферный лед (линия DIC на рис. 4). Конжеляционный лед озера Восток образуется в уникальных условиях - очень медленным намерзанием воды озера, при этом температура образовавшегося льда очень близка к точке плавления. При аналогичных условиях образуется морской лед. Газообмен в межзерновом солевом растворе морского льда происходит значительно быстрее, чем в кристаллах атмосферного льда (см. значения коэффициента диффузии в табл. 3). Однако объемная доля жидкого раствора в морском льду, обеспечивающая его высокую газопроницаемость, на несколько порядков выше, чем у конжеляционного льда озера Восток.

В предположении, что коэффициент межфазного распределения соли и газов в процессе кристаллизации $K \leq 10^{-6}$, объемное соотношение солевого раствора в конжеляционном льду может быть найдено как

$$
V_{\mathrm{B}} / V_{\text {ice }}=R_{\mathrm{mV}}(\text { B } / \text { Ice }) R_{\mathrm{Mm}}\left(\mathrm{NaCl} / \mathrm{H}_{2} \mathrm{O}\right) M_{\mathrm{NaCl}} / S_{\mathrm{B}}\left(T_{\mathrm{GA}}\right),
$$

где $R_{\mathrm{mV}}($ B / Ice $)$ - коэффициент пересчета массового отношения рассола во льду в объемное; $R_{\mathrm{Mm}}\left(\mathrm{NaCl} / \mathrm{H}_{2} \mathrm{O}\right)-$ коэффициент пересчета молярной концентрации соли 
Таблица 4. Параметры многофазной системы лед-рассол-гидраты, обуславливающие подвижность газов, содержащегося в межзерновом пространстве

\begin{tabular}{|c|c|c|c|}
\hline Наименование & Обозначение & Значение & Источник \\
\hline Среднее значение массовой доли $\mathrm{NaCl}$ во льду & $D_{\mathrm{NaCl}}=M_{\mathrm{NaCl}} / M_{\mathrm{H}_{2} \mathrm{O}}$ & $50 \mathrm{ppb}$ & {$[33]$} \\
\hline $\begin{array}{c}\text { Температура на границе между атмосферным } \\
\text { и аккреционным льдом }\end{array}$ & $T_{\mathrm{GA}}$ & -5.9 & {$[21]$} \\
\hline $\begin{array}{c}\text { Максимально возможное объемное соотношение } \\
\text { рассола во льду } V_{\mathrm{B}} / V_{\text {ice }}\end{array}$ & $V_{\mathrm{B}} / V_{\text {ice }}$ & $1.8 \cdot 10^{-6}$ & $\begin{array}{l}\text { из уравнения (5) } \\
\quad S_{\mathrm{B}}(T) \text { из [34] }\end{array}$ \\
\hline $\begin{array}{c}\text { Средний размер зерен аккреционного льда вблизи } \\
\text { границы раздела с атмосферным льдом }(h=3538 \mathrm{~m})\end{array}$ & $r_{\mathrm{G}}$ & $0.2 \mathrm{~m}$ & рис. 2 [2] \\
\hline $\begin{array}{c}\text { Среднее значение удельной поверхности зерна } \\
\text { аккреционного льда на глубине } h=3538 \mathrm{~m}\end{array}$ & $S_{\mathrm{G}} / V$ & $15 \mathrm{~m}^{-1}$ & {$[35]$} \\
\hline $\begin{array}{c}\text { Удельная протяженность границ кристаллических } \\
\text { зерен }\end{array}$ & $d I_{\mathrm{G}} / d S=C_{\mathrm{CP}} / r_{\mathrm{G}}$ & $12 \mathrm{~m}^{-1}$ & $\begin{array}{c}C_{\mathrm{SP}}=2.3 \\
\text { из рис. } 3[35]\end{array}$ \\
\hline $\begin{array}{c}\text { Максимально возможная ширина межзерновой } \\
\text { граничной области, заполненной рассолом } \\
\text { в аккреционном льду на глубине } h=3538 \text { m }\end{array}$ & $d_{\mathrm{G}}=\left(V_{\mathrm{B}} / V_{\mathrm{ice}}\right) /\left(S_{\mathrm{G}} / V\right)$ & $120 \mathrm{~nm}$ & \\
\hline
\end{tabular}

$\mathrm{NaCl}$ в массовую, $M_{\mathrm{NaCl}}$ - молярное содержание $\mathrm{NaCl}$ во льду; $S_{\mathrm{B}}\left(T_{\mathrm{GA}}\right)$ - соленость насыщенного раствора при температуре на границе атмосферного и конжеляционного льда. А молярное отношение для воздушных газов в солевом растворе будет

$$
M_{\mathrm{Air}} / M_{\mathrm{B}}=M_{\mathrm{Air}} / R_{\mathrm{Mm}}\left(\mathrm{NaCl} / \mathrm{H}_{2} \mathrm{O}\right) M_{\mathrm{NaCl}} / S_{\mathrm{B}}\left(T_{\mathrm{GA}}\right) .
$$

Если предположить, что весь газ из конжеляционного льда типа II $\left(0.001 \mathrm{~cm}^{3}\right.$ газа при температуре $20^{\circ}$ и давлении $101.325 \mathrm{kPa}$ на грамм льда [2]) содержится в солевом растворе, то вычисленное значение молярного отношения $M_{\mathrm{Air}} / M_{\mathrm{B}}=0.14$ находится близко к заполнению всего солевого раствора клатратами с формулой $\mathrm{M} / 6 \mathrm{H}_{2} \mathrm{O}$ [16] $M_{\mathrm{Air}} / M_{\mathrm{H}_{2} \mathrm{O}}=0.166$ (табл. 4). С уменьшением давления при поднятии керна с глубины газ должен перейти из клатратного состояния в состояние жидкого солевого раствора. Тогда диффузия газа в рассоле будет определять динамику дегазации керна. Модель диффузии газов в межзерновом рассоле показана линией DIB на рис. 4. Использование модели DIB дает лучшее согласие с измеренными содержаниями атмогенных газов, чем у модели DIC.

Предполагаемое из измерений содержание терригенного аргона в конжеляционном льду увеличивается с ростом глубины (рис. 5). Глубинный профиль терригенного аргона может быть описан диффузионным уравнением

$$
C(x, t)=\left(C_{0} / \pi D t\right)^{1 / 2} \exp -\left(\left(x-x_{0}\right)^{2} /(4 D t)\right),
$$

где $C(x, t)$ - концентрация в зависимости от глубины $x$ и времени насыщения (смешивания) $t, C_{0}-$ концентрация в воде, $\sqrt{D t}$ - диффузионная длина. Возрастание содержания терригенного аргона так же лучше описывается моделью DIB, чем DIC. Из расположения точек на рис. 4 можно предположить наличие смещения центра границы распространения аргона (стрелка DS) относительно границы между атмосферным и конжеляционным льдом в сторону больших глубин. Возможное объяснение такого смещения - выдавливание части солевого раствора при замерзании из атмосферного в конжеляционный лед. В процессе намерзания конжеляционного льда температура замерзания льда $-2.6^{\circ} \mathrm{C}$ перемещается к границе лед-вода, а температура атмосферного льда вблизи границы с конжеляционным льдом понижается. Следствием понижения температуры является замерзание раствора в атмосферном льду. При замерзании объем образовавшегося льда становится больше, чем раствора, из которого он образовался, и поэтому часть раствора выдавливается из атмосферного в конжеляционный лед.

Газовая смесь в системе узких пор замерзающего раствора может фильтроваться, пропуская только те компоненты раствора, молекулярные размеры которых меньше характерного диаметра пор. Таким образом, выдавленный раствор будет обогащен газами с малым молекулярным радиусом и обеднен газами с большим молекулярным радиусом. На рис. 4 стрелочками показано обогащение и обеднение газовой смеси (относительно воздушного состава), вычисленное из экспериментальных данных табл. 1. Если газ имеет большее содержание, чем в воздушной смеси под давлением в пробе, то стрелка направлена вверх, в противоположном случае - стрелка направлена вниз. Все измеренные газы - $\mathrm{H}_{2}, \mathrm{He}, \mathrm{Ne}, \mathrm{Ar}$ показали обогащение смеси. Тогда как обеднение $\mathrm{N}_{2} / \mathrm{O}_{2}$ на прямую не измерялось, а было вычислено из уравнения для трехкомпонентной смеси 


$$
\begin{aligned}
& \mathrm{Ar}-\mathrm{O}_{2} / \mathrm{N}_{2} \\
& D_{\mathrm{NO}}=\left(1-C_{\mathrm{Air}}(\mathrm{Ar})\left(C_{\mathrm{S}}(\mathrm{Ar}) / P_{\mathrm{AP}}\right)\right) / C_{\mathrm{Air}}(\mathrm{NO}),
\end{aligned}
$$

где $C_{\text {Air }}-$ содержание аргона и $\mathrm{N}_{2} / \mathrm{O}_{2}$ смеси в воздухе; $C_{\mathrm{S}}(\mathrm{Ar})$ - содержание аргона в пробе, $P_{\mathrm{AP}}-$ давление в пробах во время измерения. При обогащении аргона в 2.4 раза по сравнению с содержанием в воздухе, найденное из экспериментальных данных значение $D_{\text {NO }}=0.985$.

Приведенное рассмотрение фракционирования газовой смеси может говорить о наличии обратного осмоса в процессе нарастания конжеляционного льда. Хотя из-за больших значений погрешностей измерений предположение о возможности осмоса не может быть доказано, но приведенные данные по соотношению элементов газовой смеси находятся ближе к модели осмоса, чем к моделям диффузии.

Вытесненный солевой раствор может являться потенциальным источником химически активных элементов на границе лед-вода, важных для существования жизни вблизи этой границы [28]. В пользу гипотезы вытеснения рассола из атмосферного в конжеляционный лед говорит постепенное снижение содержания газа с увеличением глубины конжеляционного льда, без выделенной границы между разными типами льда [2]. Важным аспектом гипотезы обратного осмоса в процессе вытеснения замерзающего раствора является способность льда выполнять такую функцию клеточной мембраны как ионное фракционирование, что указывает на его возможную роль в процессе пребиотической эволюции и возникновении жизни.

\section{Заключение}

Проведено комплексное исследование содержания и изотопных соотношений благородных газов в конжеляционном льду озера Восток. Найдено, что содержание ${ }^{4} \mathrm{He}$ составляет $132 \pm 31 \mathrm{nM} / \mathrm{L}_{\text {ice. }}$ Исходя из содержания ${ }^{4} \mathrm{He}$ во льду рассчитано время обновления воды в системе озеро-грунтовая вода в двух моделях: 1) в модели грунтовых вод в подстилающих скальных породах $T_{\mathrm{LG}}=232000 \pm 69000$ years; 2) в модели глубоких осадочных пород, близкой к озеру Байкал $T_{\mathrm{LG}}=$ $=296000 \pm 86000$ years. Измерены изотопные соотношения ${ }^{3} \mathrm{He} /{ }^{4} \mathrm{He},{ }^{4} \mathrm{He} /{ }^{20} \mathrm{Ne},{ }^{20} \mathrm{Ne} /{ }^{40} \mathrm{Ar},{ }^{40} \mathrm{Ar} /{ }^{36} \mathrm{Ar}$. Из соотношения ${ }^{3} \mathrm{He} /{ }^{4} \mathrm{He}$, равного $0.29 \pm 0.08 \mathrm{R}_{\mathrm{A}}$, найден тепловой поток $62.6 \mathrm{~mW} / \mathrm{m}^{2}$, который оказался несколько выше, чем полученный в работах $[20,21] 56 \mathrm{~mW} / \mathrm{m}^{2}$.

Из соотношения атмогенных благородных газов $\mathrm{Ne} / \mathrm{Ar}$ и измереных соотношений ${ }^{40} \mathrm{Ar} /{ }^{36} \mathrm{Ar}$, указывающих на возможное наличие терригенного ${ }^{40} \mathrm{Ar}$ в пробах дегазации конжеляционного льда сделано предположение о более высокой, по сравнению с атмосферным льдом, скорости дегазации (газопроницаемости) льда. Такая высокая подвижность газов свойственна морскому льду, в котором газ находится в межзерновом солевом растворе
. Измеренное смещение границы глубинного профиля предполагаемого терригенного вклада Ar из позиции на линии раздела конжеляционного с атмосферным льдом в сторону больших глубин может говорить о вытеснении межзернового раствора с газами из атмосферного в конжеляционный лед. Выдавливание межзернового солевого раствора в ограниченном пространстве межзерновых пор, возможно, является причиной обратного осмоса, который проявляется в полученных данных как изменение относительных содержаний атмогенных газов: обеднение проб льда газами с большими радиусами молекул, и обогащение газами с малыми радиусами молекул.

\section{Благодарности}

Работа частично поддержана грантами РФФИ № 16-55-16021 НЦНИЛ_а, 16-05-00845, 15-05-08849. Авторский коллектив выражает благодарность своим коллегам Екайкину А.А. (ААНИИ), Клямкину С.Н. и Елисееву А.А. (МГУ) за полезные обсуждения и бескорыстную поддержку работы.

\section{Список литературы}

[1] Jean-Baptiste P. et al. // Letters to nature. 2001. Vol. 411. P. 460-462.

[2] Липенков В.Я. и др. // Проблемы Арктики и Антарктики. 2010. № 2. C. 85.

[3] Jean-Baptiste P., Raynaud D., Mantisi F., Sowers T., Barkov N. // Acad. Sci. Paris. 1993. 316. P. 491-497.

[4] Jean-Baptiste P. et al. // Geochimica et Cosmochimica Acta. 2010. Vol. 74. N 12. P. A461.

[5] Четвериков Ю.О. и др. // ЖТФ. Т. 61. Вып. 7. C. 1091-1096.

[6] Crank J. The mathematics of diffusion. / Oxford University press. 1975. P. 69-89.

[7] Strauss H.L., Chen Z., Loong C.K. // J. Chem. Phys. 1994. Vol. 101. P. 7177.

[8] Satoh K., Uchida T., Hondoh T., Mae S. // Proc. NIPR Symp.Polar Meteorol.Glaciol. 1996. Vol. 10. P. 73-81.

[9] Crabeck O. et al. // J. Geophys. Res.: Oceans. 2014. Vol. 119. N 10. P. 6655-6668.

[10] Kamensky I.L., Tolstikhin I.N., Vetrin V.R. // Geochim. et Cosmochim. Acta. 1990. Vol. 54. N 11. P. 3115-3122.

[11] Jean-Baptiste P. et al. // J. Environmental Radioactivity. 2010. Vol. 101. N 2. C. $185-190$.

[12] Поляк Б.Г., Толстихин И.Н., Якущени В.П. // Геотектоника. 1979. № 5. C. 3-23.

[13] Kamensky I.L., Tokarev I.V., Tolstikhin I.N. // Geochim. et Cosmochim. Acta. 1991. Vol. 55. N 10. P. 2895-2899.

[14] Mamyrin B.A., Tolstikhin I.N. Helium Isotopes in Nature. Amsterdam: Elsevier, 1974. P. 180.

[15] Ildyakov A.V., Manakov A.Yu., Aladko E.Ya., Kosyakov V.I., Shestakov V.A. // J. Phys. Chem. B. 2013. Vol. 117. P. 7756-7762.

[16] Бык С.Ш., Фомина В.И. Газовые гидраты. // Успехи химии. 1968. T. 37. № 6. С. 1097-1135.

[17] Лейченков Г.Л., Попков А.М. // Лед и снег. 2012. Т. 52. № 4. C. $21-30$ 
[18] Filina I.Y., Blankenship D.D., Thoma M., Lukin V.V., Masolov V.N., Sen M.K. // Earth and Planetary Sci. Lett. 2008. Vol. 276. P. 106-114.

[19] Дучков А.Д., Лысак С.В., Голубев В.А. и др. // Геология и геофизика. 1999. Т. 40. № 3. С. 287-303.

[20] Siegert M.J., Dowdeswell J.A. // J. Glaciol. 1996. Vol. 42. N 142. C. $501-509$.

[21] Salamatin A. N. et al. // J. Geophys. Res. 1998. Vol. 103. N 8. C. 8963-8977.

[22] Kobashi T., Severinghaus J.P., Kawamura K. // Geochim. et Cosmochim. Acta. 2008. Vol. 72. N 19. P. 4675-4686.

[23] Толстихин И.Н., Каменский И.Л., Мамырин Б.А. // Геохимия. 1969. Т. 2. С. 201-204.

[24] Bell R.E. et al. // Nature. 2002. Vol. 416. N 6878. C. 307-310.

[25] Mayer C., Siegert M.J. // J. Glaciology. 2000. Vol. 46. N 153. P. 197-205.

[26] Lin L.H. et al. // Geochemistry, Geophysics, Geosystems. 2005. Vol. 6. P. Q07003 7.

[27] Lollar B.S. et al. // Nature. 2014. Vol. 516. N 7531. C. 379-382.

[28] Bulat S. A. // Phil. Trans. R. Soc. A. 2016. Vol. 374. N 2059. P. 20140292.

[29] Manger G.E. // USGPO. 1963. 1144-E.

[30] Edgington D.N., Klump J.V., Robbins J.A., Kusner Y.S., Pampura V.D., Sandimirov I.V. // Nature. 1991. Vol. 350. N 6319. P. 601-604.

[31] Sakaguchi A. et al. // J. Paleolimnology. 2006. Vol. 35. N 4. P. 807-818.

[32] Taylor S.R. // Geochim. et Cosmochim. Acta. 1964. Vol.28. N 8. P. 1273-1285. DOI: 10.1016/0016-7037(64)90129-2.

[33] Petit J.R. et al. // Nature. 1999. Vol. 399. N 6735. P. 429-436.

[34] Assur A. // Arctic Sea Ice, Nat. Acad.Sci. Nat. Res. Council U.S.A. 1958. Vol. 598. P. 106-138.

[35] Липенков В.Я. и др. // Проблемы Арктики и Антарктики. 2007. № 76. С. $68-77$. 